\title{
Erratum to: Recommendations for Fatigue Design of Welded Joints and Components
}

\section{Erratum to:}

\section{A.F. Hobbacher, Recommendations for Fatigue \\ Design of Welded Joints and Components, IIW Collections, DOI 10.1007/978-3-319-23757-2}

In the original version of the book, the received belated corrections in Chaps. 1, 3, 6 have to be updated. The erratum book has been updated with the changes.

The updated original online version of this chapter can be found at DOI 10.1007/978-3-319-23757-2_1.

DOI 10.1007/978-3-319-23757-2_3.

DOI 10.1007/978-3-319-23757-2_6 